\title{
Peripheral Synergistic Interaction Between Lidocaine and Lumiracoxib on the $1 \%$ Formalin Test in Rats
}

\author{
Mario I. Ortiz*, ${ }^{*}$, Gilberto Castañeda-Hernández ${ }^{2}$, Jeannett A. Izquierdo-Vega ${ }^{1}$, and \\ Héctor A. Ponce-Monter ${ }^{1}$
}

\begin{abstract}
${ }^{l}$ Área Académica de Medicina del Instituto de Ciencias de la Salud, Universidad Autónoma del Estado de Hidalgo, Pachuca, Hidalgo., Mexico; ${ }^{2}$ Departamento de Farmacología, Centro de Investigación y de Estudios Avanzados del Instituto Politécnico Nacional, México, D.F., Mexico
\end{abstract}

\begin{abstract}
It has been shown that the association of non-steroidal anti-inflammatory drugs (NSAIDs) with analgesic agents can increase their antinociceptive activity, allowing the use of lower doses and thus limiting side effects. Therefore, the aim of the present study was to examine the possible pharmacological interaction between lumiracoxib and lidocaine at the local peripheral level in the rat using the $1 \%$ formalin test and isobolographic analysis. Lumiracoxib, lidocaine or fixed-dose ratio (1:1) lumiracoxib-lidocaine combinations were administered locally in the formalin-injured paw and the antinociceptive effect was evaluated. All treatments produced a dose-dependent antinociceptive effect. $\mathrm{ED}_{40}$ values were estimated for the individual drugs and an isobologram was constructed. The derived theoretical $\mathrm{ED}_{40}$ for the lumiracoxiblidocaine combination was $599.3 \pm 58.8 \mu \mathrm{g} / \mathrm{paw}$, being significantly higher than the actually observed experimental $\mathrm{ED}_{40}$ value, $393.6 \pm 39.7 \mu \mathrm{g} / \mathrm{paw}$. This result correspond to a synergistic interaction between lumiracoxib and lidocaine at the local peripheral level, potency being about one and half times higher with regard to that expected from the addition of the effects of the individual drugs. Data suggest that low doses of the lumiracoxib-lidocaine combination can interact synergistically at the peripheral level and therefore this drug association may represent a therapeutic advantage for the clinical treatment of procedural or inflammatory pain.
\end{abstract}

Keywords: Lumiracoxib, Lidocaine, Synergism, Nociception, Rats.

\section{INTRODUCTION}

Over the past few years, it has become increasingly apparent that local anaesthetics and antiarrhythmics such as lidocaine and mexilitine, offer benefit in pain. Local anaesthetics have a common chemical structure, consisting of a lipophilic aromatic ring, a link, and a hydrophilic amine group, of which most are tertiary amines. They can be classified into two groups based on the nature of the link: amides [-NH-CO-] and esters [-O-CO-]. The amide group is the most commonly used in the clinic and includes lidocaine, prilocaine, (levo-) bupivacaine and ropivacaine. The ester group includes cocaine, procaine, chloroprocaine and amethocaine. Local anaesthetics work by blocking the inward $\mathrm{Na}^{+}$current at the sodium ionophore during depolarization, which prevents propagation of the axonal action potential to the brain. By blocking the sodium channels, action potentials are no longer created, causing sensory and motor blockade [1,2]. Local anaesthetics have a unique profile in pain treatment, from topical application to produce cutaneous anaesthesia, through to spinal administration for control of labour and surgical pain, and finally to systemic administration for debilitating neuropathic pain $[2,3]$.

*Address correspondence to this author at the Laboratorio de Farmacología, Área Académica de Medicina del Instituto de Ciencias de la Salud, Universidad Autónoma del Estado de Hidalgo, Eliseo Ramírez Ulloa 400, Col. Doctores, Pachuca, Hgo., 42090, Mexico;

Tel: +52-77-1717-2000: Ext. 2361; Fax: +52-77-1717-2000: Ext. 2361;

E-mail: mario_i_ortiz@hotmail.com
Lidocaine was introduced into practice in the 1950s and, because of its excellent efficacy and safety, has become in a prototypic dental local anesthetic. Besides having excellent anesthetic efficacy, lidocaine has limited allergenicity. Many investigations have demonstrated the utility of systemic lidocaine in the treatment of postoperative, chronic and neuropathic pain $[2,4,5]$. In this same sense, subcutaneous injection or topic path of lidocaine has shown possess analgesic and anaesthesic effects in acute, postsurgical or neuropathic pain $[2,6,7]$.

Non-steroidal anti-inflammatory drugs (NSAIDs) are among the most widely used medications in the world. NSAIDs provide effective management of pain and inflammation, but a major factor limiting their use is gastrointestinal damage [8]. It has been proposed that NSAIDs-induced gastrointestinal damage involves local inhibition of the cyclooxygenase-1 (COX-1) enzyme, which generates cytoprotective prostaglandins in the gastrointestinal tract $[9,10]$. The discovery of a second isoform of the cyclooxygenase enzyme, COX-2, provided the rationale for the development of a new class of NSAIDs, the selective COX-2 inhibitors $[9,10]$. Selective inhibitors of the COX-2 enzyme, referred to as coxibs, were developed as analgesic and anti-inflammatory agents with significantly less gastrointestinal toxicity compared with traditional NSAIDs [11-13]. However, independently of their gastroprotective effects, COX-2 selective inhibitors have shown an increased risk of cardiovascular events. A recent 
meta-analysis showed that compared with placebo, ro fecoxib and lumiracoxib were associated with an increased risk of myocardial infarction (rate ratio 2.12 and 2.00, respectively) [14]. Likewise, etoricoxib and diclofenac were associated with the highest risk of cardiovascular death (rate ratio 4.07 and 3.98, respectively) [14]. On the other hand, another meta-analysis demonstrated that rofecoxib and etoricoxib appear to produce greater hypertension than either nonselective-NSAIDs or placebo; whereas celecoxib, valdecoxib and lumiracoxib appeared to have little effect on the blood pressure [15]. Therefore, cardiovascular risk needs to be taken into account when prescribing any NSAID.

Lumiracoxib is a COX-2 selective inhibitor that has showed similar efficacy to diclofenac in rat models of hyperalgesia, edema, pyresis and arthritis [16]. Similarly, lumiracoxib decreased the mechanical hyperalgesia in a model of bone cancer pain in the rat and the nociception in the rat orofacial and paw formalin tests [17-20]. At clinical level, lumiracoxib is effective for the symptomatic treatment of osteoarthritis and/or acute pain related to primary dysmenorrhea and dental or orthopedic surgery [13, 21, 22]. Lumiracoxib appears to be different from other COX-2 inhibitors in its chemical structure and pharmacological properties [13]. In postoperative dental pain, a clinical model of acute nociception, lumiracoxib exhibits a faster onset of action than other COX-2 inhibitors [22]. It is likely that this feature could be due to lumiracoxib pharmacokinetics, as this compound is readily distributed and accumulated in inflamed tissues [23]. However, it is plausible that pharmacodynamic factors are also involved in the fast onset of analgesia observed with this compound. Lumiracoxib appears to be more than a selective COX-2 inhibitor. Our group has demonstrated that lumiracoxib exhibits additional mechanisms of antinociception, particularly the activation of the nitric oxide (NO)-cyclic GMP-potassium channel pathway at the peripheral level on the formalin test [19]. Recently, it was demonstrated that lumiracoxib concentration-dependently and selectively inhibited the contraction responses to TP receptor agonists such as prostaglandin D2 and U-46619 in the tested smooth muscle preparations and the aggregation of human platelets [24].

Clinical use of mixtures of analgesics agents has increased significantly in recent years. The aim of this practice is to combine two or more drugs that have different mechanisms of action in order to achieve a synergistic interaction capable of yielding a sufficient analgesic effect at low doses. As a result, the intensity and incidence of unpleasant effects should be reduced. Currently, many different classes of drugs can serve as an effective complement to NSAIDs or opioids in the management of pain. Previously, it was found that local peripheral lumiracoxib synergistically interacts with the opioids nalbuphine and codeine in reducing the nociceptive response in the formalin test [20]. Recently, Capuano et al found a synergistic antinociceptive effect with the lumiracoxib buprenorphine combination in the rat orofacial formalin test [18]. Taken together, these findings demonstrate that lumiracoxib is able to act synergistically with opioid drugs to produce antinociception. However, there are no studies evaluating the possible interaction between lumiracoxib and some $\mathrm{Na}^{+}$channel blocker. Therefore, the purpose of the present study was to characterize whether the pre-treatment with the local peripheral administration of lumiracoxiblidocaine combination would yield more efficacious or more potent relief in the formalin model in the rat.

\section{MATERIALS AND METHODS}

\subsection{Animals}

Male Wistar rats aged 7-9 weeks (weight range: 180-220 g) from our own breeding facilities were used in this study. Efforts were made to minimize animal suffering and to reduce the number of animals used. Each rat was used in only one experiment and at the end of the experiments they were sacrificed in a $\mathrm{CO}_{2}$ chamber. All experiments followed the Guidelines on Ethical Standards for Investigation in Animals [25], and the protocol was approved by the Institutional Animal Care and Use Committee (CINVESTAV, IPN, México, D. F. Mexico).

\subsection{Drugs}

Lumiracoxib was kindly supplied by Novartis Farmacéutica (Mexico). Lidocaine and formaldehyde were purchased from Sigma (St. Louis, MO, USA). Lumiracoxib was dissolved in 50\% Tween 20 and buffer solution (sodium hydroxide and monobasic potassium phosphate; $\mathrm{pH} 8.5$ ). Lidocaine was dissolved in saline.

\subsection{Measurement of Antinociceptive Activity}

Nociception and antinociception were assessed using the formalin test, as previously described [20, 26]. Rats were placed in open Plexiglas observation chambers for $30 \mathrm{~min}$ to allow them to accommodate to their surroundings; then they were removed for formalin administration. Fifty microliters of diluted formalin (1\%) was injected s.c. into the dorsal surface of the right hind paw with a 30-gauge needle. Animals were then returned to the chambers and nociceptive behavior was observed immediately after formalin injection. Mirrors were placed to enable unhindered observation. Nociceptive behavior was quantified as the numbers of flinches of the injected paw during 1-min periods every 5 min up to $60 \mathrm{~min}$ after injection. Flinching was readily identified and characterized as rapid and brief withdrawal or flexing of the injected paw. Formalin-induced flinching behavior is biphasic. The first phase $(0-10 \mathrm{~min})$ is followed by a relatively short quiescent period, which is then followed by a prolonged tonic response (15-60 $\mathrm{min})$. The area under the curve for both phases was estimated, and a significant reduction in the area was interpreted as an antinociceptive effect.

\subsection{Study Design}

Twenty minutes before the formalin insult, animals were locally injected in the injured (ipsilateral) paw with vehicle or increasing doses of lumiracoxib (50, 100, 200 and 400 $\mu \mathrm{g} / \mathrm{paw})$, lidocaine $(100,200,400$ and $800 \mu \mathrm{g} / \mathrm{paw})$ or the lumiracoxib-lidocaine combination in $\mu \mathrm{g} / \mathrm{paw}$ (lumiracoxib 25.08 + lidocaine 43.64, lumiracoxib 50.15 + lidocaine 87.3, lumiracoxib 100.3 + lidocaine 174.6, and lumiracoxib 200.6 + lidocaine 349.15). To assess if the antinociceptive effect was due to a local action, formalin was administered in one hind paw and the highest dose tested of each drugs was injected in the non-injured (contralateral) paw. The injection volumes were $50 \mu$ l. Rats in all groups were observed regarding behavioral or motor function changes induced by 
the treatments. This was assessed, but not quantified, by testing the animals' ability to stand and walk in a normal posture. All observations were carried out by a blinded investigator.

\subsection{Data Analysis}

Results are presented as mean \pm SEM for 6-8 animals per group. Time-courses of antinociceptive response of individual drugs and the combinations were constructed by plotting the mean number of flinches as a function of time. The areas under the number of flinches against time curves (AUC) were calculated by the trapezoidal rule. AUC was calculated for the two phases of the assay and percent of antinociception for each phase was calculated according to the following equation [27, 28]:

Percent of antinociception $=\left[\left(\mathrm{AUC}_{\mathrm{vehicl}}-\mathrm{AUC}_{\mathrm{post}}\right.\right.$ compound $\left.) / \mathrm{AUC}_{\text {vehicle }}\right] \times 100$

Dose-response curves were constructed by least-squares linear regression and $\mathrm{ED}_{40} \pm$ standard error (SEM) values were calculated according to Tallarida [27]. The interaction between lumiracoxib and lidocaine was characterized by isobolographic analysis assuming that the combination is constituted by equi-effective doses of the individual drugs. Thus, from the dose-response curves of each individual agent, the dose resulting in $50 \%$ of the effect $\left(\mathrm{ED}_{50}\right)$ can be determined. However, considering a maximal effect of $100 \%$ as the total suppression of formalin-induced flinches, it appeared that lumiracoxib and lidocaine were unable to achieve a $50 \%$ response, and thus the calculation of $\mathrm{ED}_{50}$ was not feasible. Therefore, we estimated the $\mathrm{ED}_{40}$ instead of $\mathrm{ED}_{50}$ [28]. Subsequently, a dose-response curve was obtained by concurrent delivery of the two drugs (lumiracoxib plus lidocaine) in a fixed-ratio (1:1), based on the $\mathrm{ED}_{40}$ values of each individual agent. To construct these curves, groups of animals received one of the following doses of the combination: lumiracoxib $\mathrm{ED}_{40} / 2$ (200.6 $\mu \mathrm{g} / \mathrm{paw})+$ lidocaine $\mathrm{ED}_{40} / 2(349.15 \mu \mathrm{g} / \mathrm{paw})$; lumiracoxib $\mathrm{ED}_{40} / 4(100.3 \mu \mathrm{g} / \mathrm{paw})+$ lidocaine $\mathrm{ED}_{40} / 4$ (174.6 $\left.\mu \mathrm{g} / \mathrm{paw}\right)$; lumiracoxib $\mathrm{ED}_{40} / 8(50.15 \mu \mathrm{g} / \mathrm{paw})+$ lidocaine $\mathrm{ED}_{40} / 8(87.3$ $\mu \mathrm{g} / \mathrm{paw})$; lumiracoxib $\mathrm{ED}_{40} / 16(25.08 \mu \mathrm{g} / \mathrm{paw})+$ lidocaine $\mathrm{ED}_{40} / 16(43.64 \mu \mathrm{g} / \mathrm{paw})$. The experimental $\mathrm{ED}_{40}$ value for the combination was calculated from this curve.

The theoretical additive $\mathrm{ED}_{40}$ was estimated from the dose-response curves of each drug administered individually, i.e. considering that the observed effect with the combination is the outcome of the sum of the effects of each the individual drug. This theoretical $\mathrm{ED}_{40}$ value is then compared with the experimentally derived $\mathrm{ED}_{40}$ value to determine if there is a statistically significant difference [29, 30]. The theoretical and experimental $\mathrm{ED}_{40}$ values of the studied combination were also contrasted by calculating the interaction index $(\gamma)$ as follows: $\gamma=E D_{40}$ of combination (experimental) $/ E D_{40}$ of combination (theoretical). An interaction index not significantly different from unity corresponds to an additive interaction whereas values higher and lower than unity imply an antagonistic and synergistic interaction, respectively [28, 29].

\subsection{Statistical Analysis}

Dose-response data were analyzed by one-way analysis of variance (ANOVA) with Dunnet's test for post hoc comparison. Statistical significance between the theoretical additive $\mathrm{ED}_{40}$ and the experimentally derived $\mathrm{ED}_{40}$ value was evaluated using Student's $t$ test [27, 28]. An experimental $\mathrm{ED}_{40}$ significantly lower than the theoretical additive $\mathrm{ED}_{40}$ was considered to indicate a synergistic interaction between lumiracoxib and lidocaine. Statistical significance was considered to be achieved when $\mathrm{p}<0.05$.

\section{RESULTS}

\subsection{Local Peripheral Antinociceptive Effect of Lumiracoxib and Lidocaine}

The administration of formalin produced a typical pattern of flinching behavior. The first phase started immediately after the administration and then diminished gradually for the next $10 \mathrm{~min}$. The AUC of the first phase was $122.5 \pm 7.6$. The second phase started after $10 \mathrm{~min}$ and lasted until $1 \mathrm{~h}$ post administration. The AUC of the second phase was 639.3 \pm 40.8. Lidocaine, the lumiracoxib + lidocaine mixture $(\mathrm{p}<0.05)$, but not lumiracoxib $(\mathrm{p}>0.05)$, decreased the nociceptive effect induced by formalin during the first phase (Figs. 1 and 2). On the other hand, lumiracoxib, lidocaine and the lumiracoxib + lidocaine combination produced a dose-dependent antinociceptive effect during the second phase ( $<<0.05$; Figs. 1 and 2).

The $\mathrm{ED}_{40}$ value for lidocaine in the first phase of the formalin test was $511.2 \pm 24.9 \mu \mathrm{g} / \mathrm{paw}$. The $\mathrm{ED}_{40}$ values for local lumiracoxib and lidocaine in the second phase were $401.2 \pm 51.6 \mu \mathrm{g} / \mathrm{paw}$ and $698.3 \pm 84.3 \mu \mathrm{g} / \mathrm{paw}$, respectively.

\subsection{Antinociceptive Interaction of Lumiracoxib and Lidocaine After Local Peripheral Administration}

Fixed-dose ratio combinations (1:1) were prepared as described in the methods section, and these were assessed in order to construct a dose-response curve for the lumiracoxiblidocaine combination. The experimental $\mathrm{ED}_{40}$ value for the lumiracoxib + lidocaine combination in the first phase was $297.7 \pm 30.3 \mu \mathrm{g} / \mathrm{paw}$. This value was significantly lower $(\mathrm{p}<0.05)$ than the theoretical $\mathrm{ED}_{40}$, which was mentioned to be $511.2 \pm 24.9 \mu \mathrm{g} / \mathrm{paw}$.

With respect to the second phase of the test, the corresponding experimental $\mathrm{ED}_{40}$ was $393.6 \pm 39.7 \mu \mathrm{g} / \mathrm{paw}$ (Fig. 3). This value was significantly lower $(\mathrm{p}<0.05)$ than the theoretical $\mathrm{ED}_{40}$, which was predicted to be $599.3 \pm 58.8$ $\mu \mathrm{g} / \mathrm{paw}$; as it can be clearly appreciated in Fig. (3), the experimental $\mathrm{ED}_{40}$ is located below to the additive dose line. Furthermore, the interaction index $(\gamma)$ for the lumiracoxiblidocaine combination $(0.66 \pm 0.09)$ in the second phase was statistically different from unity $(\mathrm{p}<0.05)$. Thus, the data suggest that at the local peripheral level the interaction between the antinociceptive actions of lumiracoxib and lidocaine is synergistic.

\section{DISCUSSION}

The formalin test is widely used in behavioral and pharmacological nociception studies. Two phases of the response to formalin are typically observed [31]. The first phase is generally attributed to a direct effect of the algogen and excitatory aminoacids on nociceptors, whereas the second phase is related to the subsequent development of inflammation and spinal cord sensitization. Opioid analgesics exert an antinociceptive effect in both phases [20, 

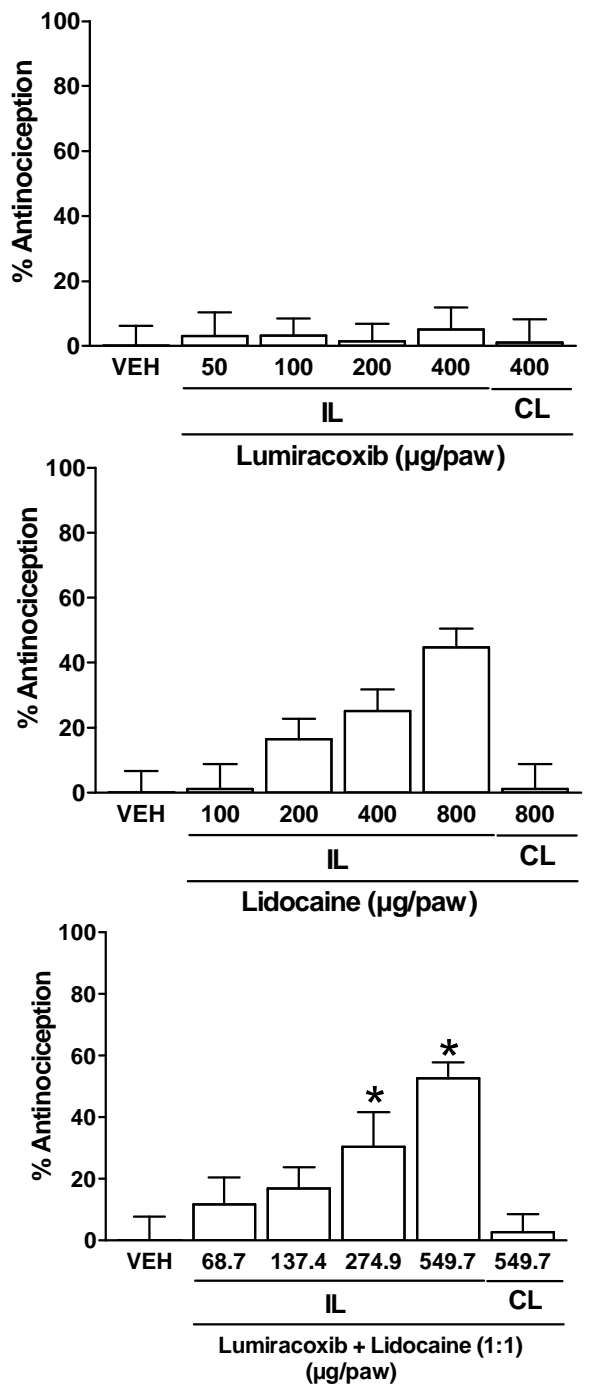

Fig. (1). Local antinociceptive effect of lumiracoxib (top), lidocaine (middle) or the lumiracoxib + lidocaine combination (bottom) in the $1 \%$ formalin test. Rats were pretreated with a local injection of vehicle (VEH), lumiracoxib, lidocaine or the lumiracoxib lidocaine combination in a fixed-ratio $(1: 1)$ into either the right (ipsilateral, IL) or left (contralateral, CL) paw, before formalin injection. Data are expressed as the percent of antinociception on the first phase. Each point corresponds to the mean \pm SEM of 6-8 animals. *Significantly different from vehicle group $(\mathrm{p}<0.05)$ as determined by ANOVA followed by Dunnett's test.

28]. In contrast, NSAIDs suppress only the second phase $[19,20,26]$. In the present study, as previously shown lumiracoxib was ineffective in the first phase of the formalin test [18-20]. On the other hand, local peripheral administration of lumiracoxib was able to decrease the second phase of the formalin test. This antinociceptive effect of lumiracoxib was not due to a systemic action since the administration of the drug in the contralateral paw was ineffective.

Lumiracoxib is the most selective COX-2 inhibitor in vitro. However, the real participation of $\mathrm{COX}-2$ in the formalin test is debatable. By one side, there are reports indicating that the COX-2 up-regulation in the rat skin is observed from 3 to 12 hours after the injury [32, 33]. By the other side, studies showed that the COX-2 expression in rat
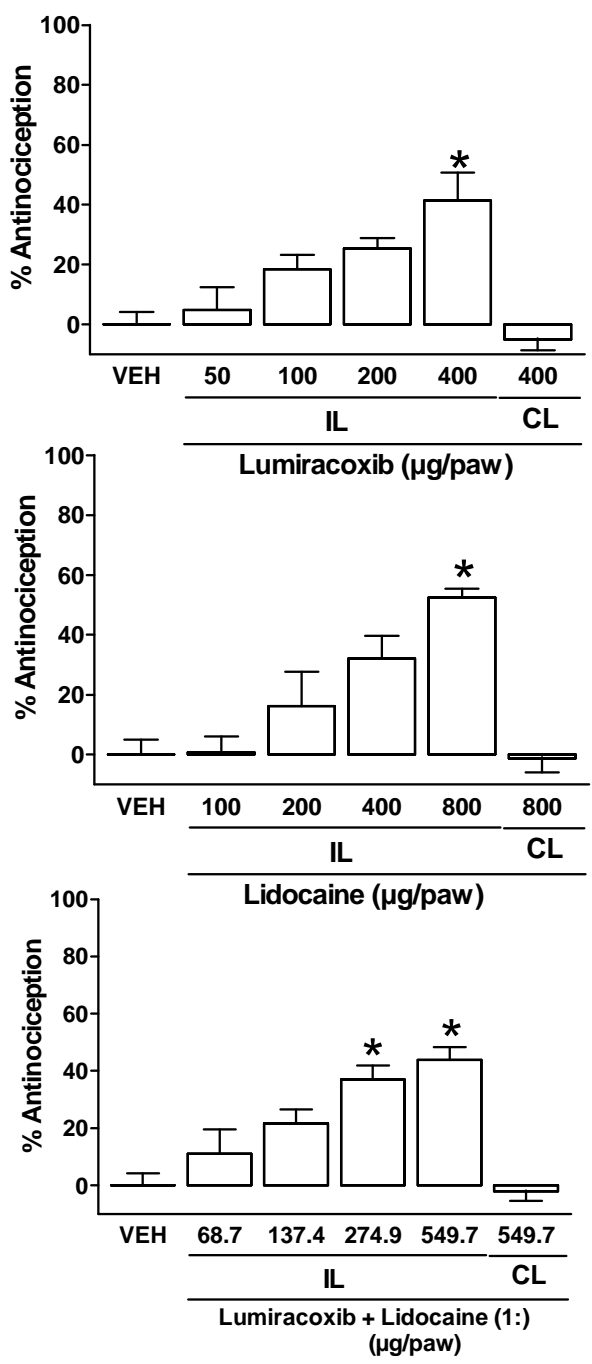

Fig. (2). Local antinociceptive effect of lumiracoxib (top), lidocaine (middle) or the lumiracoxib + lidocaine combination (bottom) in the $1 \%$ formalin test. Rats were pretreated with a local injection of vehicle (VEH), lumiracoxib, lidocaine or the lumiracoxib lidocaine combination in a fixed-ratio (1:1) into either the right (ipsilateral, IL) or left (contralateral, CL) paw, before formalin injection. Data are expressed as the percent of antinociception on the second phase. Each point corresponds to the mean \pm SEM of 6 8 animals. *Significantly different from vehicle group $(\mathrm{p}<0.05)$ as determined by ANOVA followed by Dunnett's test.

skin is constitutive and it is involved in the normal physiology of rat skin $[34,35]$. Our group showed that local peripheral administration of $200 \mu \mathrm{g} / \mathrm{paw}$ of celecoxib did not produce antinociception in the formalin test (at 1 and 5\%) [36]. Similarly, Tegeder et al. did not find any antinociceptive effect by systemic celecoxib in the same test and the spinal COX-2 mRNA and COX-2 protein upregulation reached a maximum after $2 \mathrm{~h}$ and $4 \mathrm{~h}$, respectively [37]. However, previous studies showed that local peripheral administration of the preferential COX-2 inhibitors meloxicam and nimesulide, and the selective COX-2 inhibitor celecoxib produced a significant antinociception in the formalin test [38-40]. The antinociception observed by lumiracoxib in our study agree with these last observations. Therefore, it is likely that the antinociceptive effect observed in our study could result from inhibition of prostaglandins 


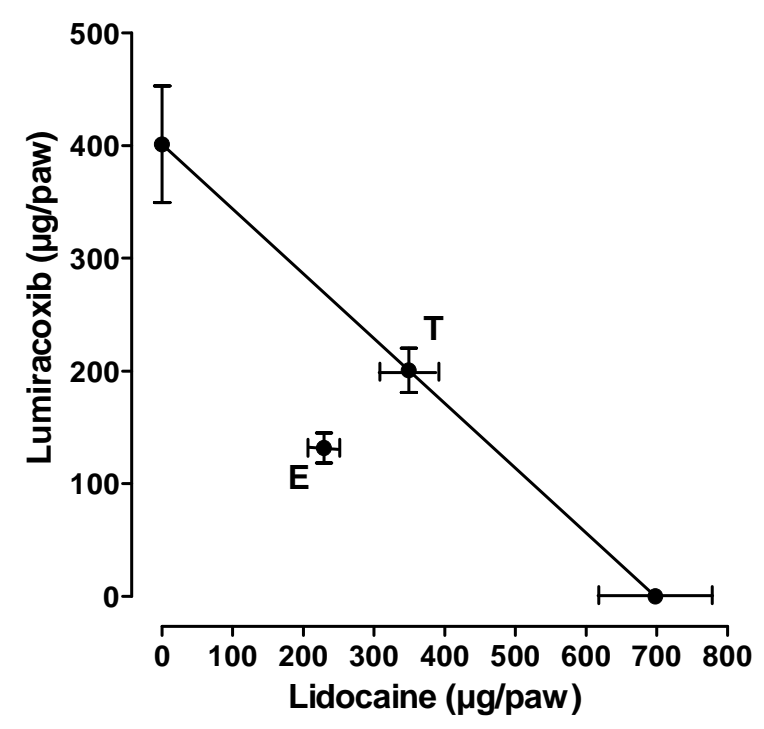

Fig. (3). Isobologram showing the peripheral interaction between lumiracoxib and lidocaine (fixed-dose ratio 1:1) at ED40 level of effect in the formalin test. The oblique line, between the $\mathrm{x}$ and $\mathrm{y}$ axes, is the theoretical additive line. The point in the middle of this line, denoted by "T", is the theoretical additive point calculated from the individual drug $\mathrm{ED}_{40}$ values. The experimental point, denoted by "E", is the actual observed $\mathrm{ED}_{40}$ value for this combination. Horizontal and vertical bars indicate the SEM.

release at peripheral level evoked by tissue injury. Nevertheless, it is accepted that some NSAIDs besides to produce in vitro and in vivo inhibition of $\mathrm{COX}$, have additional mechanisms of action [18, 19, 26, 38, 40-42]. At this respect, the antinociception observed in the present study would be due to different mechanisms, activation of the nitric oxide-cyclic GMP pathway and ATP-sensitive-, voltage-dependent-, large- and small-conductance $\mathrm{Ca}^{2+}$ activated- $\mathrm{K}^{+}$channels [19] or the inhibition of TP receptors [24].

Early surveys have shown that the application of a topical drug can be absorbed to the circulation and suffer distribution to the action site or it can alleviate local painful skin area. In placebo-controlled trials, topical treatments with capsaicin, fentanyl, clonidine, lidocaine or NSAIDs have been tested [7, 43, 44]. In the present study, lidocaine injected subcutaneously into the same area as formalin inhibited both first phase and second phase of the test. This antinociceptive action of lidocaine was not due to a systemic action since the injection of lidocaine in the contralateral paw was ineffective. These results are agreed with previous studies where lidocaine was able to decrease both phases in the formalin test $[45,46]$. Lidocaine inhibits action potential propagation via binding to membrane sodium channels, leading to a reduction in inward sodium currents and also causes the hyperpolarization of the resting membrane potential by the blockade of sodium channels that opened spontaneously under resting conditions [2, 4, 5]. For this reason, it is very probable that the inhibition of the nociception by lidocaine was due to the $\mathrm{Na}^{+}$channels inhibition. However, local anesthetics also have several other pharmacological actions, such as blocking of calcium and potassium channels and inhibition of 5- $\mathrm{HT}_{3}$ and N-methylD-aspartate (NMDA) receptors [2, 47-50]. The exact mechanisms by which lidocaine reverted the nociceptive action of formalin needs future elucidation.

In previous studies, the delivery of lumiracoxib and opioids has been demonstrated to be markedly synergistic $[18,20]$. In this sense, our group demonstrated that the local peripheral administration of nalbuphine or codeine in combination with lumiracoxib resulted in a synergistic interaction that reduced the nociception induced by the injection of formalin in the paw of the rat [20]. Furthermore, in this last study the interaction index $(\gamma)$ for the lumiracoxib-codeine and lumiracoxib-nalbuphine combinations were $0.55 \pm 0.08$ and $0.43 \pm 0.05$, respectively [20]. Likewise, the antinociceptive activity of the systemic buprenorphine - lumiracoxib combination in the rat orofacial formalin test showed a synergistic interaction with an interaction index of $0.41 \pm 0.012$ [18]. Isobolographic analysis in the present study demonstrated a synergistic interaction between lidocaine and lumiracoxib in local peripheral antinociception with an interaction index of $0.66 \pm$ 0.09 . We can see that it seems that there is a difference between the interaction indexes of the lumiracoxib - opioids combinations and the index found with the lumiracoxib lidocaine combination. It is highly likely that this difference is due to different action mechanisms between the drugs. The exact reason for this discrepancy needs to be investigated further.

On the other hand, the intrathecal administration of lidocaine and clonidine resulted in a synergistic suppression of the nociceptive response in the formalin and in the tail flick tests $[51,52]$. Likewise, it has been demonstrated that the analgesic activity of the combination of lidocaine with opioids (morphine, levorphanol, buprenorphine and endorphin-1) was synergistic in different administration pathways and assays [53-56]. Lumiracoxib may decrease the excitability of presynaptic neurons by the inhibition of TP receptor [24] and the activation of the nitric oxide-cyclic GMP pathway and $\mathrm{K}^{+}$channels [19]. Lidocaine may synergize with these effects through its ability to inhibit $\mathrm{Na}^{+}$ and $\mathrm{Ca}^{++}$channels, and 5- $\mathrm{HT}_{3}$ and NMDA receptors [45-50], which would reduce the excitability of presynaptic neurons and postsynaptic dorsal horn neurons.

\section{CONCLUSION}

Clinical outcomes of the lumiracoxib-lidocaine coadministration could include greater analgesia and probable attenuation of adverse reactions. The efficacy and benefits of this combination in clinical situations await supplementary validation.

\section{ACKNOWLEDGEMENTS}

Authors greatly appreciate the technical assistance of Martha P. González-García.

\section{CONFLICT OF INTEREST}

None declared.

\section{REFERENCES}

[1] Tetzlaff JE. The pharmacology of local anesthetics. Anesthesiol Clin North Am 2000; 18: 217-33.

[2] McLure HA, Rubin AP. Review of local anaesthetic agents. Miner Anestsiol 2005; 71: 59-74.

[3] Carr DB, Goudas LC. Acute pain. Lancet 1999; 353: 2051-8. 
[4] Glazer S, Portenoy RK. Systemic local anesthetics in pain control. J Pain Symp Manage 1991; 6: 30-9.

[5] Columb MO, MacLennan K. Local anaesthetic agents. Anaesth Intens Care Med 2007; 8: 159-62.

[6] Rowbotham MC, Davies PS, Verkempinck C, Galer BS. Lidocaine patch: double-blind controlled study of a new treatment method for post-herpetic neuralgia. Pain 1996; 65: 39-44.

[7] Meier T, Wasner G, Faust M, et al. Efficacy of lidocaine patch 5\% in the treatment of focal peripheral neuropathic pain syndromes: a randomized, double-blind, placebo-controlled study. Pain 2003; 106: $151-8$.

[8] Hernández-Díaz S, García-Rodríguez LA. Epidemiologic assessment of the safety of conventional nonsteroidal antiinflammatory drugs. Am J Med 2001; 110 (Suppl 3A): 20S-7S.

[9] Crofford LJ. COX-1 and COX-2 tissue expression: implications and predictions. J Rheumatol 1997; (Suppl) 49: 15-9.

[10] Warner TD, Giuliano F, Vojnovic I, Bukasa A, Mitchell JA, Vane JR. Nonsteroid drug selectivities for cyclo-oxygenase-1 rather than cyclo-oxygenase-2 are associated with human gastrointestinal toxicity: a full in vitro analysis. Proc Natl Acad Sci USA 1999; 9: 7563-8.

[11] Bombardier C. An evidence-based evaluation of the gastrointestinal safety of coxibs. Am J Cardiol 2002; 89: 3D-9D.

[12] Goldstein JL, Correa P, Zhao WW, et al. Reduced incidence of gastroduodenal ulcers with celecoxib, a novel cyclooxygenase-2 inhibitor, compared to naproxen in patients with arthritis. Am J Gastroenterol 2001; 96: 1019-27.

[13] Mysler E. Lumiracoxib (Prexige®): a new selective COX-2 inhibitor. Int J Clin Pract 2004; 58: 606-11.

[14] Trelle S, Reichenbach S, Wandel S, et al. Cardiovascular safety of non-steroidal anti-inflammatory drugs: network meta-analysis. BMJ 2011; 342: c7086.

[15] Chan CC, Reid CM, Aw TJ, Liew D, Haas SJ, Krum H. Do COX-2 inhibitors raise blood pressure more than nonselective NSAIDs and placebo? An updated meta-analysis. J Hypertens 2009; 27: 233241.

[16] Esser R, Berry C, Du Z, et al. Preclinical pharmacology of lumiracoxib: a novel selective inhibitor of cyclooxygenase-2. Br J Pharmacol 2005; 144: 538-50.

[17] Fox A, Medhurst S, Courade JP, et al. Anti-hyperalgesic activity of the cox-2 inhibitor lumiracoxib in a model of bone cancer pain in the rat. Pain 2004; 107: 33-40.

[18] Capuano A, De Corato A, Treglia M, et al. Antinociceptive activity of buprenorphine and lumiracoxib in the rat orofacial formalin test: a combination analysis study. Eur J Pharmacol 2009; 605: 57-62.

[19] Lozano-Cuenca J, Castañeda-Hernández G, Granados-Soto V. Peripheral and spinal mechanisms of antinociceptive action of lumiracoxib. Eur J Pharmacol 2005; 513: 81-91.

[20] Ortiz MI, Castañeda-Hernández G. Examination of the interaction between peripheral lumiracoxib and opioids on the $1 \%$ formalin test in rats. Eur J Pain 2008; 12: 233-41.

[21] Bannwarth B, Bérenbaum F. Lumiracoxib in the management of osteoarthritis and acute pain. Expert Opin Pharmacother 2007; 8: 1551-64.

[22] Kellstein D, Ott D, Jayawardene S, Fricke J. Analgesic efficacy of a single dose of lumiracoxib compared with rofecoxib, celecoxib and placebo in the treatment of post-operative dental pain. Int $\mathbf{J}$ Clin Pract 2004; 58: 244-50.

[23] Scott G, Rordorf C, Reynolds C, et al. Pharmacokinetics of lumiracoxib in plasma and synovial fluid. Clin Pharmacokinet 2004; 43: 467-78.

[24] Selg E, Buccellati C, Andersson M, et al. Antagonism of thromboxane receptors by diclofenac and lumiracoxib. Br J Pharmacol 2007; 152: 1185-95.

[25] Zimmermann M. Ethical guidelines for investigations of experimental pain in conscious animals. Pain 1983; 16: 109-10.

[26] Ortiz MI, Torres-López JE, Castañeda-Hernández G, Rosas R, Vidal-Cantú GC, Granados-Soto V. Pharmacological evidence for the activation of $\mathrm{K}(+)$ channels by diclofenac. Eur $\mathrm{J}$ Pharmacol 2002; 438: 85-91.

[27] Tallarida RJ. Drug Synergism and Dose-Effect Data Analysis. 1st. ed. New York: Chapman \& Hall/CRC Press 2000; pp.1-72.

[28] Jiménez-Andrade JM, Ortiz MI, Pérez-Urizar J, Aguirre-Bañuelos P, Granados-Soto V, Castañeda-Hernández G. Synergistic effects between codeine and diclofenac after local, spinal and systemic administration. Pharmacol Biochem Behav 2003; 76: 463-71.
[29] Tallarida RJ. The interaction index: a measure of drug synergism. Pain 2002; 98: 163-8.

[30] Tallarida RJ, Stone DJ, McCarty JD, Raffa RB. Response surface analysis of synergism between morphine and clonidine. $\mathrm{J}$ Pharmacol Exp Ther 1999; 289: 8-13.

[31] Dubuisson D, Dennis SG. The formalin test: a quantitative study of the analgesic effects of morphine, meperidine, and brain stem stimulation in rats and cats. Pain 1977; 4: 161-74.

[32] Toriyabe M, Omote K, Kawamata T, Namiki A. Contribution of interaction between nitric oxide and cyclooxygenases to the production of prostaglandins in carrageenan-induced inflammation. Anesthesiology 2004; 101: 983-90.

[33] Futagami A, Ishizaki M, Fukuda Y, Kawana S, Yamanaka N. Wound healing involves induction of cyclooxygenase-2 expression in rat skin. Lab Invest 2002; 82: 1503-13.

[34] Mayer S, Izydorczyk I, Reeh PW, Grubb BD. Bradykinin-induced nociceptor sensitisation to heat depends on cox-1 and cox-2 in isolated rat skin. Pain 2007; 130: 14-24.

[35] Xu Y, Yang L, Yang T, Xiang M, Huang E, Lian X. Expression pattern of cyclooxygenase-2 in normal rat epidermis and pilosebaceous unit during hair cycle. Acta Histochem Cytochem 2008; 41: 157-63.

[36] Torres-López JE, Ortiz MI, Castañeda-Hernández G, AlonsoLópez R, Asomoza-Espinoza R, Granados-Soto V. Comparison of the antinociceptive effect of celecoxib, diclofenac and resveratrol in the formalin test. Life Sci 2002; 70: 1669-76.

[37] Tegeder I, Niederberger E, Vetter G, Bräutigam L, Geisslinger G. Effects of selective COX-1 and -2 inhibition on formalin-evoked nociceptive behaviour and prostaglandin $\mathrm{E}(2)$ release in the spinal cord. J Neurochem 2001; 79: 777-86.

[38] Islas-Cadena M, Aguirre-Banuelos P, Granados-Soto V. Evidence for the participation of the nitric oxide-cyclic GMP pathway in the antinociceptive effect of nimesulide. J Pharmacol Toxicol Methods 1999; 42: 87-92.

[39] Veiga AP, Duarte ID, Avila MN, da Motta PG, Tatsuo MA, Francischi JN. Prevention by celecoxib of secondary hyperalgesia induced by formalin in rats. Life Sci 2004; 75: 2807-17.

[40] Ortiz MI, Castañeda-Hernández G, Granados-Soto V. Pharmacological evidence for the activation of $\mathrm{Ca} 2+-$ activated $\mathrm{K}+$ channels by meloxicam in the formalin test. Pharmacol Biochem Behav 2005; 81: 725-31.

[41] Ortiz MI, Granados-Soto V, Castañeda-Hernández G. The NOcGMP-K(+) channel pathway participates in the antinociceptive effect of diclofenac, but not of indomethacin. Pharmacol Biochem Behav 2003; 76: 187-95.

[42] Ortiz MI. Blockade of the antinociception induced by diclofenac, but not of indomethacin, by sulfonylureas and biguanides. Pharmacol Biochem Behav 2011; 99: 1-6.

[43] Watson CP. Topical capsaicin as an adjuvant analgesic. J Pain Symptom Manage 1994; 9: 425-33.

[44] Benedittis GD, Lorenzetti A. Topical aspirin/diethyl ether mixture versus indomethacin and diclofenac/diethyl ether mixtures for acute herpetic neuralgia and postherpetic neuralgia: a double-blind crossover placebo-controlled study. Pain 1996; 65: 45-51.

[45] Dallel R, Raboisson P, Clavelou P, Saade M, Woda A. Evidence for a peripheral origin of the tonic nociceptive response to subcutaneous formalin. Pain 1995; 61: 11-6.

[46] Dickenson AH, Sullivan AF. Peripheral origins and central modulation of subcutaneous formalin-induced activity of rat dorsal horn neurones. Neurosci Lett 1987; 83: 207-11.

[47] Palade PT, Almers W. Slow calcium and potassium currents in frog skeletal muscle: their relationship and pharmacologic properties. Pflugers Arch 1985; 405: 91-101.

[48] Komai H, McDowell TS. Local anesthetic inhibition of voltageactivated potassium currents in rat dorsal root ganglion neurons. Anesthesiology 2001; 94: 1089-95.

[49] Sugimoto M, Uchida I, Mashimo T. Local anaesthetics have different mechanisms and sites of action at the recombinant $\mathrm{N}$ methyl-D-aspartate (NMDA) receptors. Br J Pharmacol 2003; 138: 876-82.

[50] Ueta K, Suzuki T, Sugimoto M, Uchida I, Mashimo T. Local anesthetics have different mechanisms and sites of action at recombinant 5-HT3 receptors. Reg Anesth Pain Med 2007; 32: 462-70.

[51] Kawamata T, Omote K, Kawamata M, Iwasaki H, Namiki A. Antinociceptive interaction of intrathecal alpha2-adrenergic 
agonists, tizanidine and clonidine, with lidocaine in rats. Anesthesiology 1997; 87: 436-48.

[52] Hao S, Takahata O, Iwasaki H. Antinociceptive interaction between spinal clonidine and lidocaine in the rat formalin test: an isobolographic analysis. Anesth Analg 2001; 92: 733-8.

[53] Saito Y, Kaneko M, Kirihara Y, Sakura S, Kosaka Y. Interaction of intrathecally infused morphine and lidocaine in rats (part I): synergistic antinociceptive effects. Anesthesiology 1998; 89: 145563.
[54] Hao S, Takahata O, Iwasaki H. Isobolographic analysis of interaction between spinal endomorphin-1, a newly isolated endogenous opioid peptide, and lidocaine in the rat formalin test. Neurosci Lett 1999; 276: 177-80.

[55] Kolesnikov YA, Chereshnev I, Pasternak GW. Analgesic synergy between topical lidocaine and topical opioids. J Pharmacol Exp Ther 2000; 295: 546-51.

[56] Kolesnikov YA, Oksman G, Pasternak GW. Topical methadone and meperidine analgesic synergy in the mouse. Eur $\mathrm{J}$ Pharmacol 2010; 638: 61-4

(C) Ortiz et al.; Licensee Bentham Open.

This is an open access article licensed under the terms of the Creative Commons Attribution Non-Commercial License (http://creativecommons.org/licenses/by-nc/3.0/) which permits unrestricted, non-commercial use, distribution and reproduction in any medium, provided the work is properly cited. 